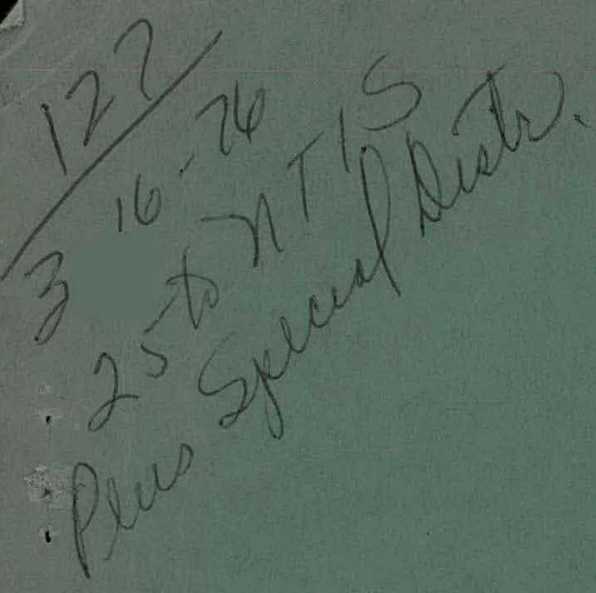

BNWL 1973

UC-20

\title{
Biomagnetic Effects: \\ A Consideration in Fusion \\ Reactor Development
}

February 1976

Prepared for the U.S. Energy

Research and Development Administration

under Contract E(45-1):1830 


\section{DISCLAIMER}

This report was prepared as an account of work sponsored by an agency of the United States Government. Neither the United States Government nor any agency Thereof, nor any of their employees, makes any warranty, express or implied, or assumes any legal liability or responsibility for the accuracy, completeness, or usefulness of any information, apparatus, product, or process disclosed, or represents that its use would not infringe privately owned rights. Reference herein to any specific commercial product, process, or service by trade name, trademark, manufacturer, or otherwise does not necessarily constitute or imply its endorsement, recommendation, or favoring by the United States Government or any agency thereof. The views and opinions of authors expressed herein do not necessarily state or reflect those of the United States Government or any agency thereof. 


\section{DISCLAIMER}

Portions of this document may be illegible in electronic image products. Images are produced from the best available original document. 


\section{NOTICE}

This report was prepared as an account of work sponsored by the United States Government. Neither the United States nor the United States Energy Research and Development Administration, nor any of their emplovees. nor any of their contractors, subcontractors, or their employees, makes any warranty, express or implied, or assumes any legal liability or responsibility for the accuracy, completeness or usefulness of any information, apparatus, product or process disclosed, or represents that its use would not infringe privately owned rights.

PACIFIC NORTHWEST LABORATORY

operated by

BATTELLE

for the

\section{U.S. ENERGY RESEARCH AND DEVELOPMENT ADMINISTRATION}

Under Contract E(45-1)-1830

Printed in the United States of America Available from

National Technical Information Service

U.S. Department of Commerce

5285 Port Roval Road

Springfield, Virginia 22151

Price: Printed Copy \$5.00; Microfiche $\$ 2.25$ 
by

D. D. Mahlum

February 1976

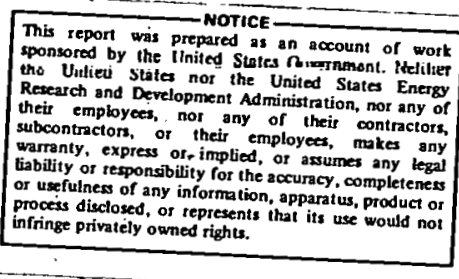

sponsored by the prepared as an account of work Research snd Dtates nor the United States Energy their employees, nor any of their sor any or warranty, express or in employecs, makes any tiability or tesponsibility for the as assumes any lezal or usefiness of any information, apparatus, product or infringe privately owned rights.

Battelle

Pacific Northwest Laboratories

Richland, Washington 99352 


\section{CONTENTS}

INTRODUCTION.

POPULATIONS OF CONCERN

SUMMARY OF LITERATURE.

HUMAN • . . . . . . . . . . . . . . . . . . 5

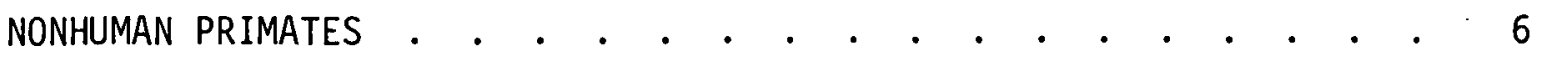

GROWTH AND DEVELOPMENT. . . . . . . . . . . . . . . . 7

BEHAV IORAL EFFECTS . . . . . . . . . . . . . . . . . 8

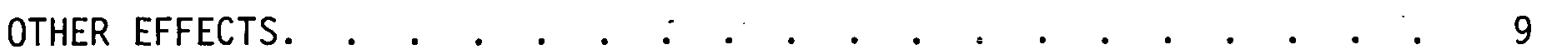

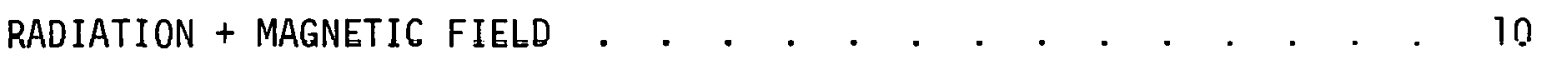

GENERAL EVALLUATION. . . . . . . . . . . . . . . . . . 13

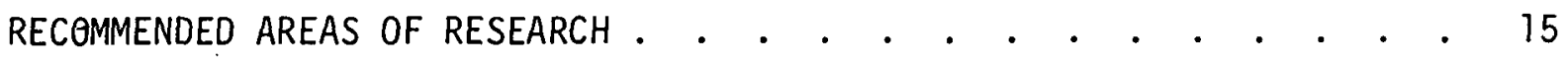

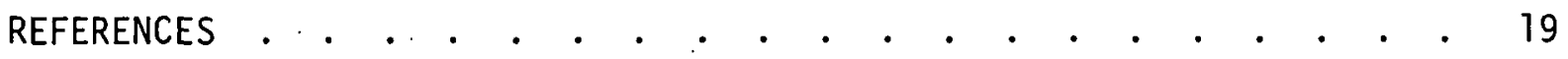

APPENDIX A: Research Areas for Examination of the Biological Effects

of Magnetic Fields . . . . . . . . . . . . . . 25 


\section{INTRODUCTION}

Fusion as a power source is receiving an increasing amount of attention. Several designs have been proposed and the feasibility of each alternative is being studied. As we move closer to a working design, attention can be paid to potential biological hazards. Large magnetic fields and the emission of tritium and lithium are unique to some fusion reactor designs.

The results of a review of the current state of knowledge concerning the biological effects of magnetic fields alone and in combination with ionizing radiation are summarized in this report. The purpose of the review is to help identify areas where additional biomedical research is needed for establishing guidelines for reactor design and operation:

Although this evaluation was made of the potential biological effects associated with operation of fusion reactors, the effects of magnetic fields may also have implications for other situations. For example, bubble chamber operations, cyclotron maintenance, eventual use of levitated trains, space travel, and work around high voltage systems may all result in exposure of people to fields greater than the geomagnetic background.

The references cited in this review represent only a fraction of the literature available on biological effects of magnetic fields. Additional material, for those who wish to obtain more detail, can be found in Busby (1967), the volumes edited by Barnothy $(1964$, 1969) the English translation of the Russian work by Presman (1970), and the recent review by Silver and Tobias (1974) as well as in the bibliographies by Manganelli (1972) and Davis, Pappajohn, and Plavinieks (1962).

Some current fusion reactor concepts rely on the use of magnetic fields to confine high temperature plasmas. The magnitude and geometry of these fields will depend on the reactor concept ultimately employed. The Tokamak and Yin Yang configurations both have a large dipole field external to the biological shield. In the theta pinch design the external magnetic field should be small due to effective cancellation of opposing field coil elements 
which leave only high order multipole moments. The laser implosion concept utilizes a modest divertor field to protect its inner wall.

The most extensive calculations and plots of magnetic field patterns were performed for the Tokamak reactor as conceived in UWMAK-I and based on a 5000 Megawatt thermal plant (Badger, et.a1., 1974). Two types of magnetic fields will be encountered in a reactor based on this concept, a toroidal field produced by the main toroidal magnetic field coils and poloidal field produced by the plasma current, divertor coils and transformer coils. The toroidal field will be generated in the plane of the torus and the strength may vary from 10,000 gauss in the area surrounding the nuclear island to $<1$ gauss at the outer edge of the reactor building (about 50 meters). Since levels of ionizing radiation will limit access to parts of the reactor building, there may be little likelihood of exposure to the toroidal field.

The poloidal field, on the other hand, will radiate both vertically and horizontally relative to the torus and will require a distance of 500 meters to reach <l gauss. Poloidal fields of several hundred gauss may be encountered by people working in the transport and hot cell regions. Conceivably, these fields could be as high as 70 to 450 gauss. People working in the region immediately surrounding the reactor building and associated facilities could be subjected to field strengths of 1 to 70 gauss for substantial periods. Beyond the horizontal plant boundaries, the field strength will have decreased to background so population exposures will not be involved. Some wildlife, particularly birds, could be exposed to field strengths in the same range as those encountered by people working in the region surrounding the reactor complex.

Certain strategies such as use of a Mu metal liner in the wall of the reactor building or redesigning the transformer to balance currents may help reduce the field strengths outside of the reactor. However, higher field strengths may be produced if the resistivity of the plasma is lower than the presently used value or if different temporal factors are used. 
Since the magnetic field strength will decrease to background levels at the plant boundaries, the general public will not be exposed to the magnetic fields of fusion reactors. The major consideration in evaluating the possible consequences of exposure of people to a high magnetic field is, therefore, directed toward personnel working in the reactor and associated facilities. This group can be considered in view of the likely makeup of its various subgroups: 1) male and female, and 2) those with a potentially greater sensitivity to insult, which include a) those with identifiable medical problems, b) those with identifiable psychological problems, c) those with medical prosthetic devices, and d) pregnant women.

Magnetic exposure of other biological material in the environment surrounding the fusion reactor will probably be of minimal consequences. An : exception to this might be birds for which evidence is accumulating that their navigation may be guided by geomagnetic information. Figure 1 illustrates that intensity of the magnetic field decreases with distance from the magnetic coils.

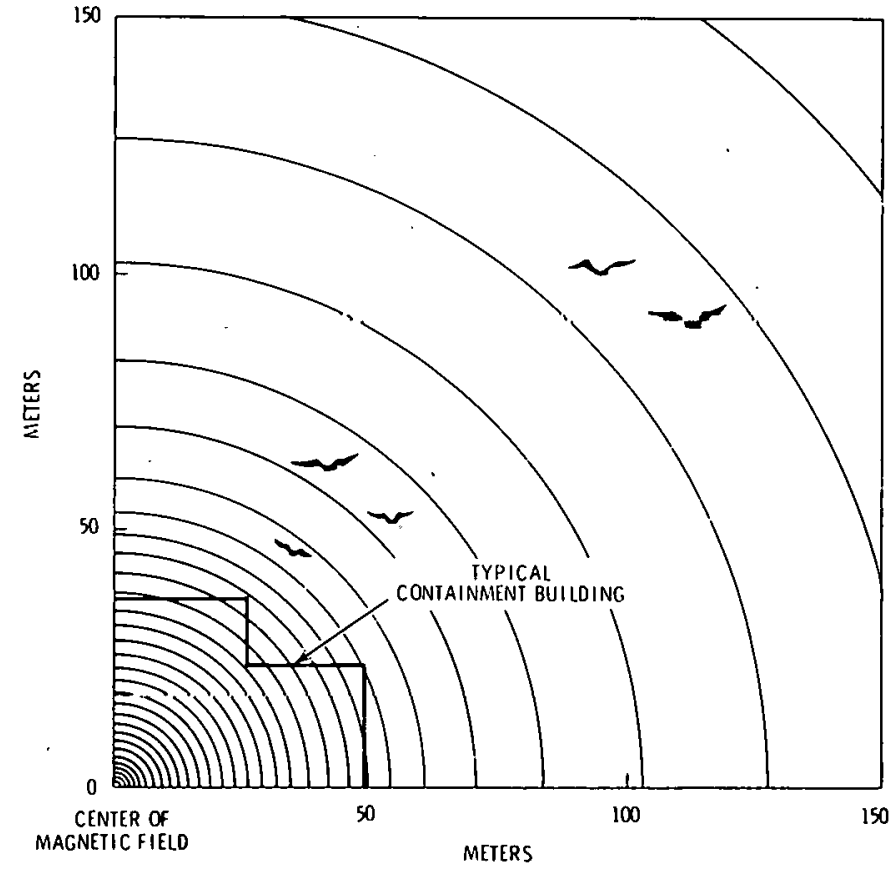

FIGURE 1. Intensity of Magnetic Field Decreases with Distance 


\section{THIS PAGE}

\section{WAS INTENTIONALLY \\ LEFT BLANK}


HUMAN

The interest of people in the biological effects of magnetic fields goes back perhaps thousands of years to the connections that people made between health and the mysterious power of the loadstone. Present day interest in this area is indicated by the efforts of investigators to correlate disturbances in the earth's magnetic field caused by solar flares with incidence of death (Duill and Dï11, 1936), mental disorders (Friedman, et a1., 1963 and 1965), and catastrophic events (Paumailloux, 1969). In any retrospective epidemiologic study, cause and effect relationships are difficult to establish and the situation with magnetic fields is no exception.

During the past hundred years, studies have been performed to determine if man is capable of responding in some way to a magnetic field. Perhaps the first documented effect in man which was consistently reproducible was that of seeing light flashes when the head was placed in an alternating magnetic field (Alexander, 1962). This phenomenon known as magnetic phosphene has been studied in detail by a number of investigators and several hypotheses advanced to explain it. Barlow, Kohn, and Walsh (1947) concluded that the retina was the probable locus of the effect and Valentinuzzi (1962) developed a mathematical model to account for the excitation mechanism. Peterson and Kennelly (1892) and Drinker and Thompson (1921), using static magnetic fields of approximately 2500 gauss, reported no observable effect when the head was placed between the magnetic poles.

Beischer, Grissett, and Mitchell (1973) have examined the response of human volunteers to an extremely low frequency (ELF) alternating magnetic field $\left(10^{-4}\right.$ webers $)$. The subjects were confined for a 1 -week period and exposed for either 10 or 22.5 hours at a time unknown to them. Measurements were made including body temperature, heart rate, respiration rate, blood pressure, electrocardiograms, effect of stress, short-term memory, psychological response, and extensive blood and urine analyses. The only significant change found was a transient rise in serum triglyceride levels after cessation of exposure. 
There are subjective studies which indicate that people exposed to magnetic fields experience a number of objectionable effects. Beischer and Reno (1971) quoted results of the Soviet studies of workers who were engaged in the fabrication of permanent magnets. No estimate of field strength was given. The Soviets reported both brady- and tachycardia and a decrease in arterial. blood pressure. The workers exhibited increased irritability, fatigue, occasional dizziness, altered appetite and headaches. Changes were found in the electroencephalograms, particularly during light stimulation. Hands were reported to exhibit a marbling pattern as well as itching, burning, and numbness. Beischer also reported that placing the hand in a 120,000 gauss field resulted in a feeling of bitter coldness and arhing of bones along with a feeling as if ants were moving over the hands.

Friedman, Becker, and Bachman (1967) exposed heads of patients to fields of 5-11 gauss modulated at either 0.1 or 0.2 cycles per second $(c / s)$. Exposure to the $0.2 \mathrm{c} / \mathrm{s}$ field slowed the reaction time significantly. Exposure to a $0.1 \mathrm{c} / \mathrm{s}$ or a static field did not alter the reaction time. No consistent changes in EEG patterns accompanied the alterations in the reaction times (Becker, 1969).

The work of Cohen (1967 and 1968) is of interest when considering the possible response of man to a magnetic field. In two very careful studies, he was able to demonstrate that there are very small magnetic fields associated with normal physiologic functions of the human body. He observed a magnetic field component which was similar to the ECG component associated with ventricular depolarization and and repolarization. He also has found magnetic fields at the surface of the scalp which appear to be produced by alpha rhythm currents of the brain.

\section{NONHUMAN PRIMATES}

Data on nonhuman primates is provided by Beischer and coworkers (1964 and 1969). They exposed squirrel monkeys to fields of 20,000 to 100,000 gauss and studied changes in the electrocardiogram. Breathing rates and R-wave amplitude were unchanged but there was a decrease in heart rate, an increase in sinus arrhythmia and an increase in the amplitude of the T-wave. Further investigation showed that part of the change in the electrocardiogram was due to an EMF generated by aortic blood flow. 
Other studies with experimental animals and isolated organs or tissues indicate that neurological, cardiac, and other muscular function can be affected by magnetic fields. However, the magnitude of the field required is usually larger than would be encountered in a fusion reactor.

\section{GROWTH ÄND DEVELOPMENT}

Immature organisms often demonstrate an enhanced sensitivity to insults of various kinds including radiation, administration of toxic drugs and metals and a variety of environmental challenges. The biochemical and physiologic processes occurring during differentiation and growth often amplify the damage that has been produced which facilitates detection and measurement of alterations inflicted by an agent. Several studies have attempted to utilize this concept for studying biomagnetic effects. Windle (1895) reported an increased incidence of malformations in the chick after exposure to an ill-defined magnetic field. However, he found no developmental abnormalities when he used the silkworm. Perakis (1941) found a retardation of development and an increased incidence of abnormalities of sea urchin eggs exposed to nonhomogenous fields of 8,800 or 43,000 gauss. A uniform field of 33,000 gauss appeared to have no effect. Beischer (1964) also reported retardation of development of the sea urchin egg with a field of 140,000 gauss. Neurath (1968 and 1969) and Levengood (1969) provide evidence for an effect of magnetic fields on development in their work with frogs and salamanders. Evidence for the importance of the stage of development was presented by Levengood. The fields used in these studies ranged between 6,300 and 17,700 gauss with large gradients.

Another study by Levengood (1966 and 1967) in which drosophila pupae were exposed to approximately 150 gauss from a magnetic probe showed that the development time was increased significantly. Moreover, when treated males were bred to untreated females, the offspring showed an increased development time. This characteristic was transmitted for 30 generations and the number of progeny from these crosses were fewer than from control matings. Treated females did not carry the trait for increased development time. The ability of a magnetic field to affect development in Drosophila was further documented by Tegenkamp (1969) who found an alteration of sex ratio as well as other genetic changes. 
Mulay and Mulay (1964) also reported nongenetic abnormalities in Drosophila. Beischer (1964), in contrast, found no effect of either homogeneous or nonhomogeneous fields on Drosophila development.

Only a few studies have been made of developmental effects using mammals. Barnothy (1963) reported that exposures of young mice to either a homogeneous or an inhomogeneous field resulted in a decreased weight gain. The effect of the homogeneous field was more than that of the inhomogeneous field, although the differences were not great. Eisenlein, Boutell and Biggs (1961), using large groups of mice approximately 3 weeks of age, found no effect of a magnetic field on weight gain over a period of 11 days. The field varied between 8,800 and 14,400 gauss.

An extremely low frequency $(0.5 \mathrm{~Hz})$ rotating field of 0.5 to 15 gauss was imposed on pregnant rats for various periods during gestation (0ssenkopp, Kolteh and Persinger, 1972). Offspring were found to have higher thyroid and testicular weights than the controls. A number of behavioral measures were also found to be altered in the magnetic field-treated animals. No differences were found in eosinophil counts, adrenal weights, blood sugar, or body weights.

\section{BEHAVIORAL EFFECTS}

There are various other pieces of evidence indicating that organisms are capable of responding to the presence of magnetic fields. Studies of behavior among nonmammalian animals indicate varying degrees of sensitivity and responsiveness to magnetic fields. A recent paper by Keeton (1974) presents evidence which shows that some species of birds depend on geomagnetic input for navigation. Keeton also refers to work which indicates that honeybees are sensitive to magnetic fields of a few gamma $\left(10^{-5}\right.$ gauss). These studies along with those which show that a diverse array of organisms can respond behaviorally to magnetic fields are important indicators of the ahility of magnetic fields to affect some biological responses. Barnwell and Brown (1964) and Brown (1966) have shown that the directional movement of both planaria and snails can be influenced by placing them in a low level magnetic field. The effect was also influenced by time of day and lunar position. Gottlieb and Caldwell (1967) found the behavior of snails to be influenced by imposition of a magnetic field. Again there was an interaction of time of day and month on the response to the 
field. The honeybee was shown to respond to a magnetic field (Caldwell and Russo, 1968). Their response tended to be a narcoleptic one in which they became rigidly fixed at a point corresponding to maximum field strength. Other studies (1966, 1970 and 1972) have shown behavioral changes for Diptera, electric fish, paramecium, and Drosophila when exposed to magnetic fields.

Experiments performed by Russell and Hedrick (1969) indicate that mice allowed to choose between a low and high magnetic environment spent more time in the lower field. However, when the number of trips from a neutral position were counted, more were made into the high field. The food and water consumption was also higher in the high magnetic field.

Persinger (1969) found that rats exposed prenatally to a low-frequency, rotating magnetic field exhibited less activity in an open-field test than did the controls. Persinger and Pear (1972) used a suppressed response paradigm to test prenatally-exposed rats and found them to be more easily suppressed than were the controls.

These varied studies indicate that a diverse array of organisms can respond behaviorally to a magnetic field. These data along with those reported for the human are important in that they show the ability of a magnetic field to affect certain biological responses.

\section{OTHER EFFECTS}

The effect of magnetic fields on biological systems has been studied in a variety of ways. Hematologic studies (1956, 1964 and 1965) have been reported and the results vary from a marked effect on leukocyte levels as found by Barnothy and coworkers (1956) to no effect as reported by Eiselein, Boutell, and Biggs (1961). Neither group found an effect of a magnetic field on erythrocyte.levels. Hackel (1964), however, using an in vitro test system, found an enhancement of erythrocyte agglutination when the reaction took place in a magnetic field. A very interesting study by Murayama (1965) showed that sickled. erythrocytes placed in a static field became oriented with their long axis perpendicular to the field.

Pathologic changes in the tissues of animals were reported by Barnothy and Sumegi (1969), Kholodov, et al. (1966) and Friedman and Carey (1969). Barnothy and Sumegi (1969) reported marked changes in the adrenal of mice after exposure 
to a 9000 gauss field for 13 days while Kholodov, et al. (1966) found severe brain lesions in rabbits in their study. When Friedman and Carey (1969) ascribed the results of the latter workers to an endemic infection found in rabbits, they also presented evidence that the effects of the infection were exacerbated by the magnetic field.

There have been many attempts to treat various diseases with magnetic fields and varying degrees of success have been reported. One of the most interesting studies was that of Pautrizel, et al. (1962) who found that mice and rats could be protected against Trypanosoma infection by treating the animals with a magnetic field. This protective effect appeared to be mediated through the humoral immune system.

\section{RADIATION + MAGNETIC FIELD}

Consideration must be given to effects of combined exposures of organisms to magnetic fields and radiation since personnel working in fusion reactors will have the potential for exposure to both.

Forssberg (1940) reported the results of an experiment to study the combined effects of magnetic fields and $x$-radiation on the survival and development of Drosophila. He found that exposure of Drosophila eggs to $165 \mathrm{R}$ while in a magnetic field resulted in a higher mortality than from radiation alone. The magnetic field in a large number of experiments increased the mortality by about $17 \%$.

Amer and Tobias (1963) found that exposure of the flour beetle, Tribolium confusum, to a magnetic field protected against radiation-induced wing abnormalities. Exposure to a magnetic field also protected against temperatureinduced abnormalities (Amer and Tobias, 1965). Results suggested that the protective effect of the magnetic field was equivalent to cooling the organism about $1.5^{\circ} \mathrm{C} / 8000$ gauss. Therefore, they examined the effect of a magnetic field field on liquid crystals which undergo changes in coloration with changes in temperature. They found that application of a 6300 gauss field resulted in a gradual change in color from blue to orange which is the same as that observed when the temperature of the liquid crystal is lowered (Amer and Tobias, 1967). 
Barnothy and Barnothy (1958) have also studied the effect of magnetic fields on survival of mice after irradiation. They found an enhanced survival if mice were first exposed to a magnetic field and then irradiated. They ascribe the protective effect to an increased leukocyte concentration found after exposure to a magnetic field.

Sikov (1968) examined the effect of simultaneous exposure of mice to radiation and magnetic fields. He found some suggestion that there was an interaction of the two agents when certain parameters were examined. The effects of the magnetic fields were not large and were somewhat inconsistent. It should be noted, however, that only acute exposures ( 30 minutes) were used so that the time available for interaction of the field with the organism was very limited. 
THIS PAGE

\section{WAS INTENTIONALLY}

LEFT BLANK 
GENERAL EVALUATION

Studies of the possible biological effects of magnetic fields should emphasize field strengths below 750 gauss since it seems unlikely that any significant exposures to higher fields will occur. However, use of higher fields will undoubtedly be necessary to fully define the experimental systems studied. It would also appear that the field will be static but inhomogenous. The organisms which are apt to encounter significant fields are humans (working personnel) and birds. The exposure to lower animal forms and plants should be of little. significance since the field will be 1 imited to the reactor area.

Studies have been performed to examine the response of biological systems to magnetic fields. Many of these have employed rather large fields for limited periods and have not used adequate numbers of experimental subjects for good statistical. analysis. The results have been highly variable and often nonreproducible.

Various biological parameters have been studied in animals exposed under many experimental conditions to magnetic fields ranging from a few gauss to 140,000 gauss. The systems studied have included electrical activity of the brain and heart, blood composition, growth and development, genetic defects, tumor growth, and function of enzymes. Several attempts also have been made to correlate human behavioral patterns with natural occurring changes in the earth's magnetic field. A substantial proportion of the many studies reported in the literature have been unable to detect any change in biological structure or function even after exposure to high intensity fields. Others have found significant changes after exposure to even low strength fields.

Changes in the electrical activity of the brain and heart have been found after exposure of humans, monkeys, rabbits, and pigeons to fields of 500 to 91,000 gauss. There have also been field studies in which correlation has been made between changes in magnetic field. and behavior. Documentation has been fairly extensive in these areas although more information is obviously needed. 
Some investigations have obtained results which suggest that preexisting lesions may be exacerbated in the presence of magnetic fields while other studies suggest that changes are due to nonspecific stress. These are important areas for further study since people with certain extant medical problems might form a sensitive subpopulation which should be identified.

The genetic effects of magnetic fields have been studied primarily in lower organisms, houseflies, and flour beetles. Changes in mortality and induction of wing abnormalities have been reported. In at least one study, there appeared to be some synergism between the effects produced by irradiation and magnetic field exposures.

Evidence for an influence of magnetic flelds on growth and development has been presented from studies on frogs, salamanders, fruit flies, sea urchins, and mice. Of the various studies reported, most have been performed at field strengths above 2500 gauss and the results have varied markedly from no effect to complete prevention of development, depending upon the laboratory performing the study.

There are reports of changes in several other biological parameters as a result of exposure to magnetic fields. Although many of the results are controversial, they do provide guidelines for design of more definitive experiments in the future. 


\section{RECOMMENDED AREAS OF RESEARCH}

A list of general information requirements for assessment of environmental effects of magnetic fields was presented in the document "Information Requirements for Controlled Thermonuclear Environmental Statements" (Young, et al., 1975) and is reproduced in Table 1.

\section{TABLE I. Information Requirements for the Assessment of Environmental Effects of Magnetic Fields(a)}

1. The magnetic field patterns for the several reactor concepts.

2. Behavioral, physiological and morphological consequences of exposure of mammals to 1 to 500 gauss fields, particularly prolonged exposures.

3. Behavioral, physiological and morphological consequences of exposure of avian species to 1 to 200 gauss fields.

4. Consequences of combined exposure of mammals to magnetic fields up to 500 gauss and to several radionuclides, particularly tritium, likely to be encountered in fusion reactor plants.

5. Consequences of exposure of people with implanted electronic medical devices to magnetic fields of 0.1 to 500 gauss.

6. Sensitivity of people with extant medical problems, recognized or subclinical, to exposure to magnetic fields, alone or in combination with radionuclides or other stresses.

7. Effects on plant systems.

8. Effects of magnetic field gradients versus constant field.

9. Effects of magnetic fields on differentiation and on the development of embryos and fetuses.

10. Development of acceptable and testable hypothesis for interaction of magnetic energy with biological material.

a. Source: J. R. Young, B. F. Gore, D. D. Mahlum, J. A. Strand, R. C. Thompson, and J. K. Soldat. Information Requirements for Controlled Thermonuclear Environmental Statements. BNWL-1.883 Battelle, Pacific Northwest Laboratories, Richland, WA, 1975. 
The items listed seem to be valid for consideration of research needs in the biomagnetic field, except for the item on effects on plant systems; since the magnetic fields will not extend beyond the fusion power plant perimeters, plant species will not be affected.

The following areas would appear to warrant the greatest attention:

- Neurologic function and behavior

Epidemiological studies and laboratory investigations indicate that behavior and other neurological functions are affected by magnetic fields. One study suggests that preexisting lesions of the braill are exacerbated by magnetic fields. This area of neurologic function and behavior warrants additional attention to carefully define changes likely to occur.

- Effects of long-term exposures

The effect of long-term exposures to magnetic fields has not been sufficiently studied. Results of studies which have been reported are in conflict. Properly designed and carefully executed long-term experiments are needed for better evaluation of the long-term effects.

- Sensitivity of immature organisms

There is evidence derived from nonmammalian studies that developing organisms are more sensitive to magnetic fields than are the mature organisms. Since the immature organism is more sensitive to many kinds of insults, it is imperative that additional attention be given to this area.

- Populations with enhanced sensitivities

Although developing organisms represent one population which may be potentially sensitive to the effects of magnetic fields, there are other populations which may have enhanced sensitivity, for example: persons with existing psychological or medical problems and those with implanted medical devices such as pacemakers or metal prosthetic devices.

- Interactions with noxious agents

Since we do not live in an isolated environment, it is important to know whether magnetic fields can act in conjunction with other noxious agents to produce an effect different from either agent alone. From the literature 
available effects could be postulated which might be additive, synergistic or antagonistic. Radiation is such an agent; there are others including cigarette smoke, and exposure to known chemical carcinogens.

- Personal dosimetery

Although adequate instrumentation is available for measurement and characterization of fields used for experimental studies, a personal dosimeter is needed to provide supporting data for epidemiological studies. The instrument should be compact enough to be easily carried by personnel working in occupational situations and yet capable of providing integrated doses under a variety of exposure conditions.

- Effects on bird navigation

It is conceivable that avian species could encounter significant fields and since there is good evidence showing the influence of magnetic fields on bird navigation, further study will be necessary to determine if the presence of the magnetic field from a fusion reactor will affect bird behavior.

- Mechanisms

More confidence can be placed in experimental data if the mechanism of action can be ascertained. At least, it is desirable to have a working hypothesis which can account for the data obtained. It seems necessary, therefore, to have additional work to derive a theory which could account for the interaction of magnetic fields and biological systems.

A systematic study of the influence of field characteristics on biological effects is needed because the question remains: Are there major differences in the biological effects produced by static, alternating, homogenous, and gradient fields and is the orientation of the organism in the field important?

As the general areas are considered further, formulation of a program in somewhat greater detail seems necessary to facilitate the orderly acquisition of applicable information. An outline of specific approaches to these problems is presented in Appendix $\dot{A}$. In these studies, it seems reasonable to emphasize the use of fields less than 750 gauss although it will be desirable to utilize higher fields to fully define the experimental system. 
These recommendations should serve as a basis for discussion among scientists active in biomagnetic research. It is anticipated that these discussions will help to refine these concepts and approaches and lead to a definitive program of research to provide the information essential to fusion needs. 


\section{REFERENCES}

Alexander, H. S. "Biomagnetics--the Biological Effects of Magnetic Fields." Am. J. Med. Electronics 1: 181-187, 1962.

Amer, N. M. "Modification of Radiation Injury with Magnetic Fields." . Rad. Res. 19: $215,1963$.

Amer, N. M. and C. A. Tobias. "Analysis of the Combined Effect of Magnetic Fields, Temperature, and Radiation on Development." Rad. Res. 25: 172-173, 1965.

Amer, N. M. and C. A. Tobias. "A Possible Explanation for the Effects of Magnetic Fields upon Biological Systems." Rad. Res. 31: 644, 1967.

Badger, B., et a1., (30 authors), UWMAK-I, A Wisconsin Toroidal Fusion Reactor Design, UWFDM-68, University of Wisconsin, Revised Mar 1974.

Barlow, H. B., H. I. Kohn, and E. G. Walsh. "Visual Sensations Aroused by Magnetic Fields." Am. J. Physiol. 148: 372-375, 1947.

Barnothy, J. M. "Growth-Rate of Mice in Static Magnetic Fields." Nature 200: 86-87, 1963.

Barnothy, M. F. (ed). Biological Effects of Magnetic Fields. Vol. 1, Plenum Press, New York, NY. 324 pp. 1964.

Barnothy, M. F. (ed). Biological Effects of Magnetic Fields. Vol: 2, Plenum Press, New York, NY. 374 pp. 1969.

Barnothy,.M. F., and J. M. Barnothy. "Biological Effect of a Magnetic Field and the Radiation Syndrome." Nature 181: 1785-1786, 1958.

Barnothy, M. F., and I. Sumegi. "Abnormalities in Organs of Mice Induced by a Magnetic Field." Nature 221: 270-271, 1969.

Barnwell, F. H., and F. A. Brown, Jr. "Responses of Planarians and Snails." Biological Effects of Magnetic Fields, M. F. Barnothy (ed). Vol. I, pp. 263-278. Plenum Press, New York, NY. 1964.

Becker, R. 0. "The Effect of Magnetic Fields Upon the Central Nervous System." Biological Effects of Magnetic Fields. M. F. Barnothy (ed). Vol. 2, pp. 207-214. Plenum Press, New York, NY. 1969.

Beischer, D. E. "Survival of Animals in Magnetic Fields of 140,000 De." Biological Effects of Magnetic Fields. M. F. Barnothy (ed). Vo1. 1; pp. 201-208, Plenum Press, New York, NY, 1964.

Beischer, D. E. "Vectorcardiogram and Aortic Blood Flow of Squirrel Monkeys (Saimiri sciureus) in a Strong Superconductive Magnet." Biological Effects of Magnetic Fields, M. F. Barnothy (ed). Vol. 2, pp. 241-259. Plenum Press, New York, NY, 1969. 


\section{REFERENCES (Cont'd)}

Beischer, D. E., J. D. Grissett, and R. E. Mitchel1. Exposure of Man to Magnetic Fields Alternating at Extremely Low Frequency. NAMRL-1180. Naval Aerospace Medical Research Laboratory, Pensacola, FL, 1973.

Beischer, D. E., J. C. Knepton, Jr. "Influence of Strong Magnetic Fields on the Electrocardiogram of Squirrel Monkeys (Samimisi sciureus)." Aerospace Medicine 35: 939-944, 1964.

Beischer, D. E., and V. R. Reno. Magnetic Fields and Man: Where Do We Stand Today? In: AGARD Conference Proceedings N. 95, Part III, Special Biophysical Problems in Aerospace Medicine. pp. C12-1 - C12-7. Aerospace Medical Panel Specialist Meeting, Luchon, France, Sep 30 - Oct 1, 1971.

Brown, F. A. "Effects and After-Effects on Planarians of Reversals of the Horizontal Magnetic Vector." Nature 209: 533-535, 1966.

Busby, D. E. Biomagnetics. Considerations Relevant to Manned Space Flight. National Aeronautics and Space Administration, Washington, DC, NASA-CR-889, $63 \mathrm{pp} .1967$.

Caldwell, W. E. and F. Russo. "Exploratory Study of the Effects of an A.C. Magnetic Field Upon the Behavior of the Italian Honeybee (Apis mellifica)." J. Genetic Psychol. 113: 233-252, 1968.

Cohen, D. "Magnetic Fields Around the Torso: Production by Electrical Activity of the Human Heart." Science 156: 652-654, 1967.

Cohen, D. "Magnetoencephalography: Evidence of Magnetic Fields Produced by A1pha-Rhythm Currents." Science 161: 784-786, 1968.

Davis, L. D., K. Pappajuhn, and I. M. Plavinleks. "Blbllography of the Blolog1cal Effects of Magnetic Fields." Fed. Proc. 21 (5, Part II): 1-38, 1962.

Drinker, C. K. and R. M. Thompson. "Does the Magnetic Field Constitute an Industrial Hazard?" J. Indust. Hygiene 3: 117-129, 1921.

Dü11, T. and B. Dü11. "Correlations Between Disturbances in Terrestrial Magnetism and Frequency of Deaths." Deutsch Medizinische Wochenschrift 61: 95, 1935.

Eiselein, J. E., H. M. Boutell, and M. W. Biggs. "Biological Effects of Magnetic Fields--Negative Results." Aerospace Med. 32: 383-386, 1961.

Friedman, H. and R. J. Carey. "The Effects of Magnetic Fields Upon Rabbit Brains." Physiol. Behavior 4: 539-541, 1969.

Friedman, H., R. O. Becker, and C. H. Bachman." Effect of Magnetic Fields on Reaction Time Performance." Nature 213: 949-950, 1967.

Friedman, H., R. 0. Becker, and C. H. Bachman." Geomagnetic Parameters and Psychiatric Hospitals Admissions." Nature 200: 626-628, 1963. 


\section{REFERENCES (Cont'd)}

Friedman, H., R. O. Becker, and C. H. Bachman. "Psychiatric Ward Behaviour and Geophysical Parameters." Nature 205: 1050-1052, 1965.

Forssberg, A. "Some Experiments in Irradiating Drosophila Eggs with RoentgenRays and $\gamma$-Rays in a Magnetic Field." Acta Radiologica 21: 213-220, 1940.

Gottlieb, N. D. and W. E. Caldwell. "Magnetic Field Effects on the Compass Mechanism and Activity Level of the Snail Hel isoma duryi endiscus." J. Genetic Psychol. 111: 85-102, 1967.

Hematologic Studies

Barnothy, J. M., M. F. Barnothy, and I. Boszormenyi-Nagy. "Influence of a Magnetic Field Upon the Leucocytes of the Mouse." Nature 177: $577-578,1956$.

Barnothy, M. J. Hematological Changes in Mice. Biological Effects of Magnetic Fields. M. F. Barnothy (ed). Vol. I, pp. 109-126. Plenum Press, New York, NY, 1964.

Hackel, E. "Magnetic Field Effects on Erythrocyte Agglutination." Vox Sang. 9: 60-64, 1964:

Murayama, M. "Orientation of Sickled Erythrocytes in a Magnetic Field." Nature 206: 420-422, 1965.

Keetion, W. T. "The Mystery of Pigeon Homing." Scientific American 231: 96-107, 1974.

Kholodov, Y. A., M. M. Alexandrovskaya, S. N. Lukanova, and R. A. Chizhenkova. "Effects of a Constant Magnetic Field on the Nervous Tissue Structures." In: Third International Biomagnetic Symposium, (abstract), pp. 37-39, 1966.

Levengood, W. C. "A New Teratogenic Agent Applied to Amphibian Embryos." J. Embryol. Exp. Morphol. 21: 23-31, 1969.

Levengood, W. C. "Cytogenetic Variations Induced With a Magnetic Probe." Nature 209: 1009-1013, 1966.

Levengood, W. C. "Morphogenesis as Influenced by Locally Administered Magnetic Fields." Biophys. J. 7: 297-307, 1967.

Manganel1i, L. A. Biomagnetism: An Annotated Bibliography. The George Washington University Medical Center, Biological Sciences Communication Project, Washington, DC, 187 pp. 1972. 
Mulay, I. L. and L. N. Mulay. "Effect on Drosphila Melanogaster and S-37 Tumor Cells; Postulates for Magnetic Field Interactions." Biological Effects of Magnetic Fields, M. F. Barnothy (ed). Vo1. 1, pp. 146-169. Plenum Press, New York, NY, T964.

Neurath, P. W. "High Gradient Magnetic Field Inhibits Embryonic Development of Frogs." Nature 219: 1358-1359, 1968.

Neurath, P. W. "The Effect of High-Gradient, High-strength Magnetic Fields on the Early Embryonic Development of Frogs." Biological Effects of Magnetic Fields. M. F. Barnothy (ed). Vol 2, pp. 177-187, Plennum Press, New York, NY, 1969.

Ossenkopp, K. P., W. T. Koltek, and M. A. Persinger. "Prenatal Exposure to an Extremely Low Frequency--Low Intensity Rotating Magnetic Field and Increases in Thyroid and Testicle Weight in Rats." Developmental Psychobiol. 5: 275-285, 1972.

\section{Other Studies}

Becker, G. "On the Orientation of Diptera According to the Geomagnetic Field." In: Third International Biomagnetic Symposium, (abstract), pp. 9-11, 1966.

Kogan, A. B., I. N. Goltseva, L. I. Dorojkina, and T. S. Sachava. "Changes in the Motion Pattern of Paramecium caudatum Under the Influence of a Static Magnetic Field." In: Third International Biomagnetic Symposium, (abstract), p. 12, 1966.

Wehner, R. and Th. Labhart. "Perception of the Geomagnetic Field in the F1y Drosophila mclanogastcr." Expcrcntia 26:967-968; 1970.

Werber, M., R. M. Sparks, and A. C. Goetz. "The Behavior of Weakly Electric Fish (Sternarchus albifrons) in Magnetic Fields." J. Gen. Phsychol. 86: $3-13, .1972$.

Pautrizel, R., A. Priore, F. Berlureau, and A. N. Pautrizel. "Stimulation, by Hhysical Means, of the Jefenses in the Mouse and in the Kat Against Experimental Trypanosomiasis." Comp. Rend. Acad. Sci., Ser. D. 268: 1889-1892, 1969.

Perakis, N. "On the Physical Chemistry of the Sea Urchin Egg and Its Development in a Magnetic Field." Bull. d'Histologic Appliquee 18: 115-132, 1941.

Persinger, M. A. "Open-Field Behavior in Rats Exposed Prenatally to a Low Intensity-Low Frequency, Rotating Magnetic Field." Develop. Psychobiol. 2: $168-171,1969$. 


\section{REFERENCES (Cont'd)}

Persinger, M. A. and J. J. Pear. "Prenatal Exposure to an ELF-Rotating Magnetic Field and Subsequent Increase in Conditioned Suppression." Develop.

Psychobiol. 5: 269-274, 1972.

Peterson; F. and A. E. Kennelly. "Some Physiological Experiments with Magnets at the Edison Laboratory." New York Med. J. 56: 729-732, 1892.

Poumailloux, M. Repercussions Humaines de l'activité Solaire Interne. Cah Call. Med. Hosp. Paris 10: 1201-1214, 1969.

Presman, A. S. Electromagnetic Fields and Life. Plenum Press, New York, NY, $366 \mathrm{pp}$. Translated from Russian by F. L. Sinclair and F. A. Brown, Jr. 1970.

Russel1, D. R. and H. G. Hendrick. "Preference of Mice to Consume Food and Water in an Environment of High Magnetic Field." Biological Effects of Magnetic Fields, M. F. Barnothy (ed). Vol. II, pp. 233-239. Plenum Press, New York, NY, 1969.

Sikov, M. R. Simultaneous Influence of Magnetic Fields and Ionizing Radiation Upon Mammals or Mammalian Systems. Final Technical Report to the Air Force (Contract. No. F41609-67-C-0014), May 1968.

Silver, I. L., and C. A. Tobias. "Magnetic Fields and Their Biological Effects:" Space Radiation Biology and Related Topics. pp. 257-31.2. Academic Press, Inc., New York and London, 1974.

Tegenkamp, T. R. "Mutagenic Effects of Magnetic Fields on Drosophila Melanogaster." Biological Effects of Manetic Fields, M. F. Barnothy (ed). Vol. 2, pp. 189-206. Plenum Press, New York, NY, 1969.

Windle, B. C. A. "On the Effects of Electricity and Magnetism on Development." J. Anat. Physiol. 29: 346-351, 1895.

Young, J. R., B. F. Gore, D. D. Mahlum, J. A. Strand, R. C. Thompson, and J. K. Soldat. Information Requirements for Controlled Thermonuclear Environmental Statements. BNWL-1883. Battelle, Pacific Northwest Laboratories, Richland, WA, 1975. 
THIS PAGE

WAS INTENTIONALLY

LEFT BLANK 
APPENDIX

RESEARCH AREAS FOR EXAMINATION OF THE BIOLOGICAL

EFFECTS OF MAGNETIC FIELDS

I. Behavioral Studies

A. Animals with normal behavior patterns (rodents and primates)

1. Variety of tests for neurologic and behavioral effects.

2. Conditions of exposure to magnetic fields.

a. Static Fields

1) Varying field strengths

2) Uniform versus gradient fields

3) Animal position varied relative to orientation of field

4) Varying exposure times

b. Alternating Fields

1) Wide range of frequencies.

2) Variation of conditions as for static fields

B. Animals with abnormal behavior patterns

1. Employment of models used for other behavioral studies such as for psychosis or neurosis.

2. Similar exposure conditions as for normal animals.

II. Moderate and Long-term Studies (rodents)

A. Use 3 month exposure under wide range of field conditions

1. Hematologic and clinical chemistry studies

2. Growth

3. Pathologic changes in variety of organs

4. Functional changes

a. Electrophysiologic measures

1) ElecLrocardiogram (ECG)

2) Electroencephalogram (EEG)

b. Liver function

c. Measures of circadian rhythm

d. Simple behavioral tests 
5. Response to stress (cold, heat, electrical shock, or swimming performance)

B. Life span studies

1. Selected field conditions

2. Most measures used under short term study (II-1)

3. Spontaneous tumor incidence

III. Effects on Development

A. Lower organisms (to obtain large numbers of test animals for statistical purposes, fish may be an excellent system)

1. Static and alternating fields

2. Morphologic development

3. Behavioral develupilenl

4. Ability to cope with stress
a. Cold
b. Predation

B. Rodents

1. Varying field conditions (static versus alternating; uniform versus gradient)

2. Reproductive performance of exposed adults ?
a. Fertility
b. Litter size
c. Incidence of malformed offspring
d. Sex ratios of offspring

3. Yostnatal performance
a. Growth
b. Survival to weaning
c. Neurologic and behavioral development
d. Physiologic fitness
e. Reproductive ability
f. Tumor incidence
g. Other pathology 
IV. Combined Exposures

A. Radiation + magnetic fields

1. External radiation + magnetic field

2. Internal emitters + magnetic fields

a. Tritium

b. Prolonged exposures

B. Drug and dietary insult

1. Alcohol + magnetic field

a. Alcohol + magnetic field

b. Pathologic effects of alcohol

c. Behavioral consequences associated with alcohol intake

2. Iron deficiency + magnetic field

a. Hematologic changes

b. Serum chemistry evaluation

C. Smoking

D. Exposure to carcinogens

V. Survey and Evaluation of People Presently Exposed to Magnetic Fields

A. Evaluation of exposure conditions.

B. Routine medical evaluation

C. Behavioral evaluation

VI. Effects on Birds

A. Behavioral

1. Homing behavior

2. Migration

B. Functional

VII. Mechanisms of Interaction of Magnetic Fields with Biological Material

A. Cellular studies

B. Subcellular studies

C. Molecular studies

VIII. Development of a Personal Dosimeter 


\section{OFFSITE}

A. A. Churm ERDA Chicago Patent Group 9800 S. Cass Avenue Argonne, IL 60439

J. W. Beal

ERDA Div. of Controlled Thermonuclear Research Washington,. DC 20545

M. M. Cohen ERDA Div. of Controlled Thermonuclear Research Washington, DC 20545

E.N.C. Dalder

ERDA Div. of Controlled Thermonuclear Research Washington, DC 20545

S. 0. Dean

ERDA Div. of Controlled Thermonuclear Research Washington, DC 20545

R. L. Hirsch ERDA Div. of Controlled Thermonuclear Research Washington, DC 20545

R. N. Kostoff ERUA Div. of Controlled Thermonuclear Research Washington, DC 20545

B. G. Twining

ERDA Div. of Controlled Thermonuclear Research Washington, DC 20545

T. C. Reuther ERDA Div. of Controlled Thermonuclear Research Washington, DC 20545

J. M. Williams ERDA Div. of Concrolled Thermonuclear Research Washington, DC 20545

C. R. Finfgeld

ERDA Div. of Controlled Thermonuclear Research Washington, DC 20545

J. N. Grace

ERDA.Div. of Controlled Thermonuclear Research Washington, DC 20545

L. Bogart

ERDA Div. of Controlled Thermonuclear Research. Washington, DC 20545
2 F. E. Coffman ERDA Div. of Controlled Thermonuclear Research Washington, DC 20545

\section{B. Miller}

ERDA Div. of Controlled Thermonuclear Research Washington, DC . 20545

2 K. H. Zwilsky ERDA Div. of Controlled Thermonuclear Research Washington, DC 20545

G. A. Kolstad ERDA Division of Physical Research Washington, DC 20545

M. E. Rose ERDA Division of Physical Research'

Washington, DC 20545

27 ERDA Technical Information Center

M. S. Kaminsky Argonne National Laboratory 9700 South Cass Avenue Argonne, IL 60439

P. M. Persiani

Argonne National Laboratory 9700 South Cass Avenue Argonne, IL 60439

M. Petrick

Engineering and Technology Division

Argonne National Laboratory 9700 South Cass Avenue Argonine, IL 60439

W. E. Parkins, Manager Atomics International Component Engineering and Technology Division North American Rockwell P.0. Box 309 Canoga Park, CA 91304

D. Gurinsky Brookhaven National Laboratory U.S.E.R.D.A Brookhaven Area Office Upton, NY 11973

S. Pearlstein

Brookhaven National Laboratory Livermore, CA 94550 U.S.E.R.D.A.

Brookhaven Area Office

Upton, NY 11973

G. R. Hopkins

261 Sweeney Hall
J. R. Powell

Brookhaven National Laboratory

U.S.E.R.D.A.

Brookhaven Area Office

Upton, NY 11973

A. J. Impink, Jr. Carnegie Mellon University

Pittsburgh, PA 15213

R. A. Gross

Plasma Research Laboratory

236 Sw Mudd Bldg.

Columbia University

New York, NY 10027

W. C. Gough

Electric Power Research Inst.

3412 Hillview Ave.

Palo Alto, CA 94304

Gulf General Atomic

P.0. Box 1111

San Diego, CA 92112

Zeinab Sabri

Iowa State University

Nuclear Engineering Department Ames, IA 50010

R. Borg

Lawrence Livermore Laboratory

P. 0. Box 808

Livermore, CA 94550

A. Carl Haussmann

Lawrence Livermore Laboratory P.0. Box 808

Livermore, CA 94550

R. F. Post

Lawrence Livermore Laboratory P.0. Box 808

Livermore, CA 94550

C. J. Taylor

Lawrence Livermore Laboratory P.0. Box 808

Livermore, CA 94550

R. Werner

Lawrence Livermore Laboratory

P.0. Box 808

Livermore, CA 94550

L. L. Wood

Lawrence Livermore Laburatury P.0. Box 808

\section{Distr-1}


W. Bauer

Division Supervisor of

Physical Research

Sandia Labs Livermore

Livermore, CA 94550

D. J. Dudziak

Los Alamos Scientific

Laboratory

CTN Research

P.0. Box 1663

Los Alamos, NM 87544

D. B. Henderson

Los Alamos Scientific

Laboratory

CTN Research

P.0. Box 1663

Los Alamos, MM 07544

F. L. Rlue

Los Alạnos Scientific

Laboratory

CTN Research

P. O. Rnx $16 \hbar .3$

Los Alamos, NM 87544

L. Stewart

Los Alamos Scientific

Laboratory

CTN Research

P.0. Box 1663

Los Alamos, NM 87544

A. L. Bement

Professor of Nuclear Materials

Dept. of Nuclear Engineering

Massachusetts Institute of

Technology

77 Massachusetts' Ave.

Cambridge, MA 02139 .

Bruno Coppi

Department of Physics

Massachusetts Institute of

Technology

Cambridge, MA 02139

L. Lidsky

Dept. of Nuclear Engineering

Massachusetts Institute of

Technology

Cambridge, MA 02139

David Rose.

Massachusetts Institute of

Technology

Cambridge, MA .02139

R. E. Stickney

Mechanical Engineering

Massachusetts Institute of

Technology

Cambridge, MA 02139
J. J. Reinmann

NASA - Lewis Research Center

2100 Brookpark Rd.

Cleveland, $\mathrm{OH} 44135$

Vincent Arp

National Bureau of Standards

Cryogenics Division

Boulder, CO 80302

A. P. Fraas

Oak Ridge National Laboratory P.0. Box $Y$

Oak Ridge, TN 37830

J. Rand McNally, Jr. Oak Ridge National Laboratory P.0. BoX Y

Oak Ridge, TN 37830

0. Steirier

Oak Ridue National Laboratory

P.O. Box $Y$

Oak Ridge, TN 37830

J. Scott

Oak Ridge National Laboratory

P. 0. Box $X$

Oak Ridge, TN 37830

J. Banford

Physics International

2700 Merced St.

San Leandro, CA 94577

R. A. Huse

Public Service Electric and Gas Co.

80 Park Place

Newark, NJ .07101

R. Q. Mills

Princeton University

P.0. Box 451

Princeton, NJ $08540^{\circ}$

E. C. Tanner

Princeton University

P.0. Box 451

Princeton, NJ 08540

V. L. Teofilo

Dept. of Aerospace and

Mechanical Science

Princeton University

P.0. Box 451

Princeton, NJ 08540

H. Perkins

Dept. of Chemistry

Princeton University

Princeton, NJ 06540
R. E. Gold

303 Sayre Hall

Forestal Campus

P. 0. Box 451

Princeton, NJ 06540

M. Kristiansen

Texas Tech. University.

Lubbock, TX 79409

A. F. Haught

United Aircraft Research Lab.

United Aircraft Corporation

East Hartford, CT 06108

L. Levine

U.S. Naval Research Laboratory

Washington, DC 20390

C. Z. Serpan, Jr.

U.3. Naval Researich Laboratory

Washington, DC 20390

Francis Chen

University of cal! fornia

Department of Electrical

Engineering

Los Angeles, CA 90024

A. J. Lichtenber

University of California

Electronics Research

Laboratory

College of Engineering

Berkeley, CA ÿ4720

C. D. Hendricks

University of Illinois

Nuclear Enyineering Laboratory

Urbana, IL' 61801

G. H. Milcy

IIniversity of Ill1nols

Nuclear Enyineering Laboratory

Urbana, IL 6180 I

\section{Terry Kammash}

University of Michigan

Nurlear Fng ineering Department

Ann Arbor, MI 48105

Dean Abrahamson

University of Minnesota

School of Public Affairs

Social Science Building/309

Minneapol is, MN 55455

W. G. Davéy

University of Texas

Department of Physics

Austin, TX 78712

E. Linn Draper, Jr.

University of Texas

Department of Physics

Austin, TX 78712

Distr-2 
W. E. Drummond University of Texas

Department of Physics

Austin, TX 78712

Abrahami Hertzberg

University of Washington

Aerospace Research Laboratory

316 Guggenhe im

Seattie, WA 98105

A. L. Babb

University of Washington

Nuclear Engineering Department

Seattle, WA 98105

R. Conn

University of Wisconsin

Nuclear Engineering Department

Madison, WI 53706

G. L. Kulcinski

University of Wisconsin

Nuclear Engineering Department

Madison, WI 53706

C. U. Haynarei

University of Wisconsin

Nuclear Engineering Department

Madison, WI 53706

\section{Lichtman}

Department of Physics

University of Wisconsin

Milwaukee, WI 53201

$\overline{\bar{c}} \overline{\bar{c}}$. Eurraidsoii

Hashington State University

Department of Physics

Puliman, HA 99163

J. W. Baum

Brookhaven National Laboratory

Upton, NY 11973

C. E. Easterly

Health Physics Division

Oak Ridge National Laboratory

Oak Ridge, TN 37830

G. Ketchum

Health \& Industrial Hygiene Division

Oak Ridge National Laboratory

Oak Ridge, TN 37830

\section{J. N. Luton}

Thermonuclear Division

Oak Ridge National Laboratory

Oak Ridge, TN 37830

C. A. Tobias

Biology \& Medicine Division

University of California

LBL

Berkeley, CA 94720
T. F. Budinger

Biology \& Medicine Division

University of California

LBL

Berkeley, CA 94720

M. L. Minthorn

ERDA

Division of Biomedical and

Environmental Research

Washington, DC 20545

C. E. Cartér

ERDA

Division of Biomedical and

Environmental Research

Washington,. DC 20545

T. K. Fowler

Assoc. Director for Controlled

Thermonuclear Research

University of California

LLL

Livermore, CA 94550

H. A. Kornberg

Electrical Power Research Inst.

Palo Alto, CA. 94303

J. D. Grissett

Naval Aerospace Medical Research Laboratory

Pensacola Naval Air Station

Pensacola, FL 32512

D. E. Beischer

1917 Frontier St. 4-F

Durham, NC 27705

D. A. Pinyan

Senior Safety Officer

National Accelerator Lab.

P.0. Box 500

Batavia, IL 60510

$R$. Huson

Accelerator Division

National Accelerator Lab.

P.0. Box 500

Batavia, IL 60510

R. W. Flugumi

Division of Electric Energy Systems

ERDA

20 Massachusetts Avenue

Washington, DC 20545

W. E. Mott

Environmental Control Technology

ERDA

Washington, DC 20545
D. Janes

USEPA

9100 Brookville Road

Silver Spring, MD 20910

S. M. Michaelson

Department of Radiation Biology

University of Rochester

Rochester, NY 14642

H. J. Healer

Office of Telecommunication Policy.

1800 G Street, N.W.

Washington, DC 20545

D. M. Ross, Chief

Health Protection Branch

ERDA

Division of Operational Safety

Washington, DC 20545

K. R. Baker

EROA

Division of Operational Safety Washington, DC 20545

M. A. Bell

ERDA

Division of Operational Safety

Washington, DC 20545

D. D. Mahlum (15)

ERDA

Division:of Ricmedica! and Environmental Research

Washington, DC 20545

\section{Distr-3}


ERDA Richland Operations Office

B. M. Melton

\section{Battelle-Northwest}

D. T. Aase

G. S. Allison

T. W. Ambrose

D. G. Atteridge

D. A. Baker

J. L. Bates

M. A. Bayne

E. R. Bradley

J. L. Brimhali

R. L. Brodzinski

L. R. Bunnell

L. L. Burger

N. E. Carter

T. D. Chikalla

R. G. Clark

S. D. Dahigren

M. T. Dana

D. E. Deonigi

R. I. . Dillon

P. J. Dionne

B. H. Duane

J. W. Finnigan

5

5

J. C. Fox

J. J. Fuquay

J. E. Garnier

B. F. Gore

W. J. Gray

O. K. Harling

A. J. Haverfield

$U$. P. Jenquín

A. B. Johnson, Jr

R. H. Jones

T. J. Kabele

J. D. Kaser

W. S. Kelly

H. E. Kissinger

R. A. Kntt.wit?

N. Laegried

B. R. Leonard, Jr.

Hanford Engineering

Development Labs

\section{T. T. Claudson}

D. L. Lessor

H. B. Liemohn

R. C. Lijikala

R. F. Maness

5 R. P. Marshail

R. D. Nelson

D. F. Newman

R. E. Nightingale

D. E. Oiesen

5 L. T. Pedersen

R. T. Perry

D. R. Pratt

L. L. Rader

L. A. Rancitelli

J. F. Remark

D. S. Renne

W. D. Rishmond

W. F. Sandusky

5 L. C. Schmid

N. M. Sherer

E. P. Simonen

R. I. Smith

J. K. Soldat

C. H. Stewart

K. B. Stewart

5 R. W. Stewart

J. A. Strand

D. L. Styris

A. M. Sutey

G. L. Tingey

M. T. Thomas

J. K. Thompson

T. J. Trapp

R. Wang

R. E. Westerman

L. D. Williams

s. R. Young

M. G. Zimmerman

Technical Publications

Technical Information

Distr-4 